\title{
Redizer as palavras, refazer as coisas: João Maimona e o lugar outro na poesia de Angola
} Otávio Henrique Meloni (UFF - PG/UFRJ)

\author{
desenhar assim as palavras \\ era transmitir aos dedos do pé a brevíssima lição \\ por elas inventada. hoje multiplico e eternizo \\ a finíssima relva d'alegria. \\ João Maimona
}

É sempre extenuante falar e analisar poesia e isso se agrava quando direcionamos nosso olhar para um contexto tão plural e cheio de peculiaridades como o das literaturas africanas de língua oficial portuguesa. Não se trata apenas de questões lingüísticas ou culturais das diversas etnias e dos diferentes países que se incluem neste recorte, mas há um distanciamento político-temporal que provém de sua condição colonial tão tardia, somente extirpada nos meados da década de setenta do século passado.

Todos esses fatores comungados num universo de guerras coloniais, engajamento político e a miséria humana formam uma literatura basicamente panfletária que, durante um bom tempo, segue a risca palavras de ordem contra o colonizador e de incentivo a revolta e a revolução. Não estamos aqui incluindo toda a produção literária desses países, até por que seria arbitrário totalizar autores e obras quando são notáveis os casos que fogem a essa regra e já utilizam um maior experimento estilístico, lingüístico e temático ainda nesse conturbado período.

No rastro dessa literatura que cavalga palavras em direção a independência política, ânimos e expectativas constroem um universo que se volta para um único ponto objetivo. Assim, quando em 1975, a independência política de Angola é declarada pelo líder do MPLA e poeta Agostinho Neto, há, após o instante inicial de euforia popular, um estanque desta produção literária. Encontramos eco dessa constatação em entrevista de Luandino Vieira, um dos poucos autores que mesmo na época da literatura mais política já experimentava novas formas de escrita, a Michel Laban em 1988:

\footnotetext{
"Estes últimos doze anos são um período de crise porque uma mudança tão radical como seja passar um território do seu estatuto de colônia para um estatuto de país independente - haja ou não haja alterações substanciais na infra-estrutura ou na superestrutura - é um facto muito radical, e todo o facto radical provoca uma crise, pelo menos enquanto ele continuar a repercutir sobre a sociedade, até ao ponto de a sociedade o ir absorvendo, se
} 
coadunar com esse choque, depois dominar esse choque e passar a, como se diz em francês. "maitriser" isso que ela própria provocou... (...) Portanto, a crise é uma relação entre factores que nos são impostos e outros que nós produzimos como sociedade." (VIEIRA, p. 412; 1988)

Luandino alerta Laban que a literatura angolana vive um momento de estagnação por um simples motivo: os autores que ainda escrevem e são remanescentes daquele período da colonização se alfabetizaram literariamente como colonizados e, segundo Luandino, escrevem sobre isso e continuam, ainda hoje (1988), escrevendo sobre isso e os autores mais jovens ainda não se encontram nas letras nem na conturbada situação política pós-colonial, seguida prematuramente de uma nova guerra, agora civil. Esse período de crise na produção literária toma um bom número de anos no percurso da literatura de um país jovem enquanto independente $(1975$ - 1988). Porém será na década de oitenta que alguns nomes começarão a surgir com mais destaque por se arriscarem em projetos literários diferentes, não mais marcados por um experimentalismo estético que não se define nem se questiona, mas assinalados por peculiaridades locais, lingüísticas e traços pessoais da cada autor. Essa nova geração é apontada ainda timidamente pelo próprio Luandino e reúne autores como Ruy Duarte, Paula Tavares e o aqui trabalhado João Maimona.

Esse pequeno panorama que apresentamos sobre a literatura angolana colonial e pós-colonial, se faz importante para o que aqui queremos discutir dentro da poesia do João Maimona: A criação de um lugar outro através do trabalho com a linguagem dentro do campo do poema. Assim, perceber como este universo literário angolano se formou sobre os fortes alicerces de uma produção poética baseada no combate e no engajamento político, repleta de palavras de ordem, é o ponto de partida para entendermos esse processo de transição temática e de estilo, que veremos também com Paula Tavares e Rui Duarte, só que de maneira distinta, já que esses baseiam suas respectivas obras num olhar mais direto aos seus locais de origem e as tradições destes locais. Maimona nos entregará, aos poucos, um verdadeiro inventário de reorganização sintática e semântica do poema e do espaço que pretende transpor para e através de suas palavras.

Com uma carreira amplamente premiada, na qual encontramos dois Prêmios Sagrada Esperança e um terceiro lugar do concurso de poesia da ABL, João Maimona desde cedo se demonstrou diferente e inovador no quadro da literatura angolana - não à toa seu primeiro livro Trajectória Obliterada (1985) já recebe a maior gratificação literária do país. Com um histórico de exilado no Congo Léopoldville nos tempos da guerra civil, se formou e manteve profundo contato com a língua francesa durante a juventude, Maimona retorna para Angola em 1978, fixando-se no norte do país, mais precisamente na província do Huambo, onde ajudou a fundar a Brigada Jovem de Literatura Alda Lara. É membro da União dos Escritores Angolanos e deputado na Assembléia Nacional. Esse é João Maimona, poeta representativo da atual movimentação literária angolana, portador de uma nova proposta para e com a linguagem e suas possíveis representações e resignificações através do campo e do trabalho com o poema.

Estabelecendo essas considerações acerca do poeta angolano, prosseguimos nossa análise evidenciando o livro Festa de Monarquia (2001). Esse será o nosso referencial para tratar as questões aqui propostas e para instaurar um vínculo com outras obras do próprio autor e referências possíveis em seu universo poético. Festa de Monarquia reúne diversas peculiaridades em sua formação que valem ser comentadas enquanto parte representativa da constituição da obra. Dividido em dois grandes e independentes blocos - o que fica claro para um leitor mais atento - o livro reúne, na verdade, duas obras distintas apresentadas num mesmo volume.

O primeiro bloco ou poemário se chama Retrato das Mãos. Prefaciado por 
Inocência Mata, este conjunto de poemas toma boa parte do livro e é subdividido em dois momentos: I - Escrita Presença ; II - Sementes. Já o segundo bloco de poemas é intitulado Epilepsia do planeta e já recebe outro prefácio, agora do crítico galego Xosé Lois García. Epilepsia não sofre subdivisões a apresenta um conjunto de poemas uníssonos, no qual o ritmo e a seqüência dos textos proporcionam uma sensação de continuidade semântica. Com essa estrutura peculiar, Festa de Monarquia se apresenta terreno amplo para análises, principalmente no que diz respeito à construção de uma linguagem poética preocupada com a palavra e o sujeito que a profere.

Já no poema que serve de auto-epígrafe do livro, de nome Prelúdio, encontramos os traços primários do que a obra seguirá a desenvolver no decorrer das páginas. Apresentando um movimento interno e de constante reestruturação através do verso, Prelúdio anuncia o conjunto de poemas que segue de maneira limpa e reveladora, delineando espaços, temas e técnicas que Maimona continuará a desenvolver e praticar na obra. Cabe ainda ao texto de introdução do livro um caráter redentor, no qual o poeta já projeta seu compromisso com a linguagem e com o estabelecimento do eu poético, dentro ou fora do próprio texto:

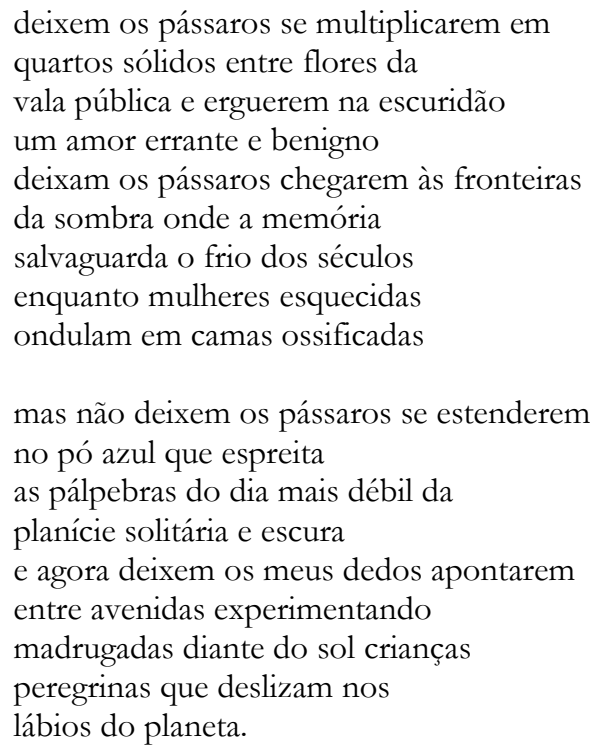

Percebemos o tom anunciativo do poema e seus movimentos de impessoalidade-pessoalidade, seqüência e recorte, que culminam num pedido/convite do autor, quase uma justificativa de canto, para começar a apresentar seus poemas. Prelúdio não só passa a ser parte de uma obra peculiar, como já assinalamos aqui, mas interfere na leitura dos poemas seguintes, exercendo seu poder pleno de epígrafe e ao mesmo tempo inaugurando estratégias poéticas que Maimona articulará no decorrer da obra.

O primeiro bloco de poemas que constitui Festa de Monarquia, reúne cinqüenta e um poemas subdivididos em dois momentos. Neste bloco intitulado Retrato das mãos, João Maimona apresenta uma poesia de vasta experimentação lingüística e temática apoiada sempre na dinamização do verso e na valorização da palavra. o que salta aos olhos numa primeira leitura deste poemário é a maneira como o poeta desenvolve suas reflexões sociais e humanas de maneira fragmentária e corroída aproveitando, para isso, o campo físico do poema.

Redimensionado para o trabalho com a palavra, o universo poético de João Maimona se desdobra aqui em duas direções. A primeira estabelece um diálogo entre o campo vocabular e as experiências pessoais e coletivas do autor, retomadas pelo campo 
da memória e de suas reinvenções espaciais e físicas para o passado e o presente. A segunda diz respeito ao constante repensar do poema durante seu 'fazimento', parafraseando Eugênio Coserio, e sobre sua própria estrutura de representação da linguagem através do intenso trabalho executado pelo autor. $O$ retrato das mãos, portanto, deixa de ser apenas título e incorpora o próprio exercício poético de Maimona, metaforizando esses dois pontos de análise através da referência a parte do corpo responsável pela escrita e da presença do retrato enquanto reconstituição de um momento, nesse caso, o momento da criação.

Em prefácio ao citado bloco de poemas, Inocência Mata chama atenção para o papel de remitologização da palavra no ambiente poético de Maimona. Ela ainda ressalta que este processo tem como grande mérito trazer para dentro do texto, em sua organização espacial, tensões sociais e humanas que poderiam passar desapercebidas numa poesia tão preocupada com a questão da forma e da depuração da escrita. Inocência mata nos mostra que:

(...) se é possível falar-se de uma "finitude do real", a poesia de Maimona opera uma infinitização do real e à palavra cabe o papel de remitologização do mundo (também através de metáforas inusitadas e de conjugação de paradoxos), porque ela, a palavra, se torna responsável pela nomeação das coisas e dos eventos na poesia _ e a verdade da palavra poética foi salvaguardada em Maimona.(MATA, 2001, p.30)

Com a palavra poética 'salvaguardada', João Maimona se sente livre para se apropriar da técnica do verso e parte em busca de uma recriação semântica para os signos da terra angolana, as tradições e suas próprias memórias de infância e de vida. É a partir desse trabalho e das citadas metáforas, por Inocência Mata, que o campo desse poemário se desenvolve. Retrato das mãos representa um concílio de tensões que se relacionam e medem forças na produção e na expectativa do verso.

Memória que aliás, parece-nos ser o fio condutor de toda a composição de Festa de Monarquia, quando pensamos no campo temático dos poemas. O processo e aprisionamento de imagens, em metáforas às vezes inusitadas - como já nos disse Inocência Mata - em palavras e no próprio conjunto semântico dos poemas, comprova essa importância das reminiscências pessoais e coletivas que acompanham o poeta em seu percurso. São várias as citações da infância, da própria palavra memória e suas derivações que encontramos dentro de seus versos:

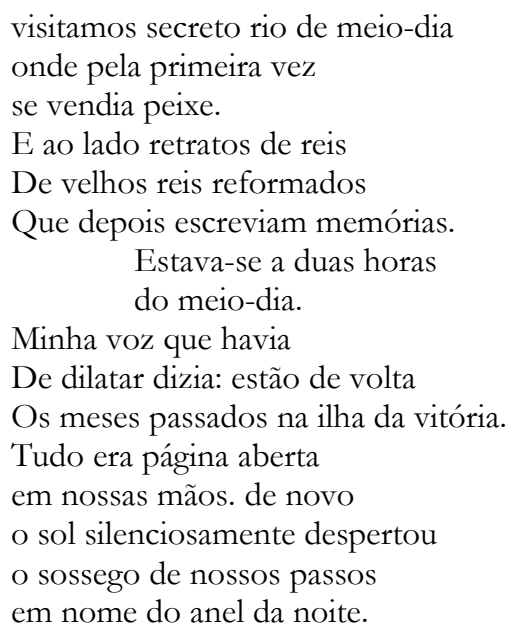

Como podemos ver no poema mãos e coisas, João Maimona intercala dois sujeitos poéticos - individual e coletivo - para evidenciar a recriação mnemônica de um espaço por ele próprio assinalado como passado, onde reis reformados escreviam 
memórias. Essa relação entre o lembrar e o aprisionar na linguagem é uma constante na poesia do jovem angolano. Maimona, na seqüência do poema, quando abandona a coletividade do ato para assumir a voz do poema, transforma o processo num silencioso e pessoal compreender e captar de poesia. A voz que ainda havia de dilatar retorna nos últimos versos ao coletivo, mas deixa marcado seu registro individual, com uma única fala, porém fundamental: "estão de volta/ os meses passados na ilha da vitória." A materialidade do voltar é oferecida pela linguagem enquanto representação possível, ainda que inventada, de um passado já ido. Como esse 'material' mnemônico é ficcionalizado e muitas vezes reinventado, a palavra serve como instrumento conciliador entre os tempos que se reúnem no poema. Segundo Blanchot: "A linguagem é aquilo que destrói o mundo para fazê-lo renascer no estado de sentido, de valores significados." (BLANCHOT,) assim, como instrumento de destruição e de reorganização, a linguagem serve a Maimona como potência de duas vias, primeiro fragmentando um ambiente poético repleto de marcas peculiares e históricas e reorganizando-o, na forma e no campo temático, posteriormente. $\mathrm{O}$ movimento das duas ações parece ser constante e simultâneo, como se essa 'destruição' fosse o princípio instaurador do poema e da nova ordem das coisas. Lembrando mais uma vez de Inocência Mata, trata-se de uma remitologização das coisas através da palavra poética.

Através desse processo, Maimona estabelece um novo contato com o mundo e com as coisas que conhecemos. A palavra poética adquire um valor diferente e criador que o poeta evidencia tanto na solidão vocabular como no conjunto do poema:

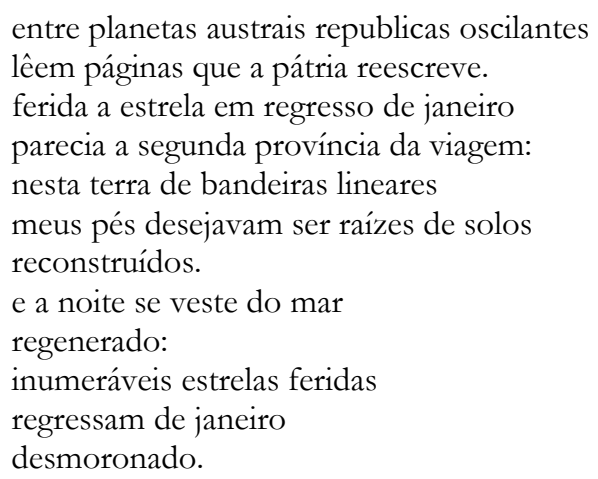

Palavras como reconstruídos e regenerado apontam diretamente para a resignificação que a palavra propõe, mas é ainda latente o que o campo semântico do poema expressa na conjugação de imagens e cenas criadas por Maimona, como nos primeiros versos do poema. Há ainda de interessante para ressaltar a retomada da idéia inicial no momento crucial do poema. Isso não ocorre somente neste texto, intitulado: Maturação - já de sugestivo nome. É um processo corrente na obra de Maimona, através do qual percebemos sua intenção de redizer, semântica e linearmente, a matéria de sua poesia.

Nesse momento encontramos novamente em Blanchot um eco para as propostas que João Maimona incorpora, nesse momento, em sua produção poética:

\footnotetext{
A palavra só tem sentido se nos livra do objeto que ela nomeia: ela deve nos poupar de sua presença ou do 'concreto lembrete'. Na linguagem autêntica, a palavra tem uma função, não apenas representativa, mas também destrutiva, ela faz desaparecer, torna o objeto ausente, anula- o . (BLANCHOT, p.36)
}

Essa anulação do objeto não é negativa, nem mesmo entrega a palavra poética um papel totalitário dentro do universo poético de Maimona, mas e logicamente, torna-a indispensável para sua compreensão. O que se passa na poesia do angolano é a palavra assumindo papel principal, relegando as coisas que representa, direta e indiretamente, 
num outro plano que não precisa ser notado como signo primordial. Para Maimona a palavra tem força e poder de renomear, assim nos afasta do 'concreto lembrete' - citado por Blanchot - e nos insere num outro universo de possibilidades e riscos, baseado numa linguagem recriadora.

Se a perspectiva teórica de Blanchot se encaixa bem nesses casos, é ainda através dela que vamos transpor o trabalho poético de Maimona com as palavras para a relação de entrega e a criação de um lugar outro, no campo da linguagem, para a sobrevivência criativa do autor. O poema se transforma num espaço de vida e, consecutivamente, de morte para o poeta e para seus possíveis sujeitos poéticos. O risco de Maimona reside na apropriação da linguagem enquanto espaço criador e criativo para suas reflexões pessoais e coletivas. Através do afastamento referencial das coisas concretas e das significações da palavra, o poeta estabelece uma espécie de exílio dentro do campo do poema, fechando-se numa pessoalidade às vezes dúbia e/ou inexistente:

\title{
1. instante inicial
}

eis a história das sílabas igualando os confins das linhas de água. a alegria peregrina percorre cidadelas como as sentinelas do mar: as águas vêm dar à beleza das sílabas como se houvesse um luminoso reencontro: era o instante inicial.

\section{2. primeiro instante intermédio} esperava que a paisagem pintasse noites vizinhas. E insígnias rebuscando cacimbos numa desconhecida povoação. Porém, apareceram riozinhos esverdeados Iluminando armadilhas, angústias E telas infernais: nascia a nação comum Encerrando torturas sobre as lágrimas.

\section{3. segundo instante intermédio}

\author{
parecia um reino de passo fascinante \\ suficiente para enriquecer estômagos estranhos. \\ precioso? os rios não diziam o contrário. \\ e desfilava maldita miséria insuficiente \\ para desencantar a plenitude humana. \\ em reino que raspava a fortuna \\ crescia a flor do dia freqüentando \\ abraços virgens. ricos em sonhos enfeitiçados.
}

\section{4. instante final}

teria o solo da eternidade outras cinzas?
onde adormece o abrigo crescem
um insondável silêncio e delicadas
folhas cuja cor saúda a origem da sombra:
todas as cinzas pronunciavam a eternidade.
Era a repetição dos passos e imagens.
Imagens do milênio anterior.

O poema acima, de nome Acalmia ruidosa. Em quatro sinos, nos parece uma grande referência para exemplificar esse movimento que, através da linguagem, cria esse lugar outro para o poeta. Dividido em quatro momentos, separados cuidadosamente por nomeações que sugerem uma seqüência criativa, o poema estabelece um novo espaço. 
Os quatro instantes se repartem em fragmentos de uma história da qual o sujeito poético em primeira pessoa só parece participar no segundo fragmento, através do verbo 'esperava' que também pode ser lido como indefinido por terceira pessoa. Cria-se, no decorrer do poema a instauração do lugar através das sílabas que, metonimicamente, representam a linguagem. Em seguida as coisas (rios, povoações, nação) vão surgindo como conseqüência do instante inicial e se agravam em ações negativas no terceiro momento. Só quarto instante, o instante final, temos o reencontro da voz do poema com seus próprios questionamentos, ainda que não representada por uma marca de primeira pessoa, singular ou plural. O poema, nitidamente, refaz um percurso comum a João Maimona transpondo crítica social para o seu peculiar universo poético, porém evidencia uma diferente maneira de estabelecer esse contato com questões exteriores criando um novo espaço de representação, com novas imagens e novas abordagens, sempre respaldado na linguagem como base criativa e sustentadora. Assim, a idéia de exílio dentro do poema convive com a criação deste lugar outro em que o poeta, mais a vontade, pode, através e com a linguagem redimensionar questões e possibilidades assumindo o risco paradoxal que a própria linguagem impõe.

Esse é o caminho de Retrato das mãos. Um caminho de múltiplas vias, todas através da linguagem. É por ele que João Maimona percorre em busca de sua palavra poética e de suas resignificações dentro de um novo universo, uma gênese das coisas refeitas e reditas. Nesse bloco inicial de Festa de Monarquia, encontramos um poeta e um eu lírico que se conjugam, ora individual, ora coletivamente para trabalhar com a linguagem, a metáfora/metonímia constante das mãos - tanto no título quanto no correr de alguns poemas - deixa clara a idéia do sentir a escrita, da importância dessa escrita manualmente refeita a cada descoberta de verso.

Dentro do mesmo livro Festa de Monarquia, encontramos um novo bloco de poemas - Epilepsia do Planeta - que, de uma certa forma, ultrapassa a proposta de Retrato das mãos. Não se trata de uma questão de qualidade dos versos, ou de melhor encontro com as palavras. Estamos falando de uma proposta que se projeta mais ousada no que diz respeito à dinamização do verso e da própria temática.

Um tanto menor que o bloco anterior, Epilepsia do planeta atinge um ponto temático quase profético e místico. Aqui João Maimona põe sua palavra poética a serviço de um universo real que se decompõe e que só pode ser retratado e recomposto através da linguagem. Anunciando um momento de agonia (epilepsia) Maimona transporta para seus textos uma tensão entre a impossibilidade da linguagem, o reposicionamento do eu lírico e a visão que estabelece com o mundo. A linguagem, sempre tão exigida e revisitada nas análises sobre a poesia do jovem angolano, ganha aqui um novo aspecto com relação aos momentos anteriores: ela passa a se 'descolar' do eu. Assim, nalguns poemas desse bloco encontramos a total ausência de um eu poético atuante ou transmissor da verdade e da referência dentro do campo do poema, como veremos adiante.

Em texto que constitui prefácio de Epilepsia do Planeta, o crítico galego Xosé Lois Garcia nos informa:

Maimona, com este livro, irrompe de novo na poesia angolana posicionando-se cima desses lamentáveis excessos e dessas carências na qual incorrem vários poetas ancorados no seu passado sem abrir referências de futuro. Diremos que maimona teve sempre essa preocupação de abrir parâmetros novos e isto verifica-se nos seus primeiros livros poéticos da década dos oitenta e noventa. Ele soube criar esse universo poético tão pessoal para dinamizar alguns conteúdos que agora resultam ser de grande interesse para nós, tanto no que se refere à qualidade como à facilidade expressiva que se contempla nessa obstinada e progressiva reconstrução da memória colectiva africana. (GARCIA, 2001, p.98) 
Xosé nos mostra como a poesia de João Maimona é sempre baseada numa busca incessante pelo momento poético, sem se perder em vazias insistências estéticas. Com esse preâmbulo quase de preparação, o crítico nos mostra ainda que apesar de estar sempre atrelado a memória pessoal e coletiva, Maimona não abdica de uma poesia que visa e aponta sempre para o futuro. Daí seu constante processo de re - (reconstrução, resignificação, reestruturação, restabelecimento, reapropiação, etc.) no qual encontramos os dois movimentos: o da memória como imagem e força primeira do processo e a projeção, através da linguagem, de uma nova significação para esta memória.

É em "Epilepsia do planeta" que Maimona dá um salto para a criação do que chamamos de um lugar outro dentro da escrita poética angolana. Não que seja apenas aqui que isso acontece, mas podemos dizer que neste poemário, Maimona atinge um ponto distinto pelo conjunto temático, vocabular e lingüístico que estabelece em seus poemas. Lembrando novamente de Xosé Garcia:

Esta mobilidade simbolista exibida em fragmentações metafóricas vem a ser um gênero atípico na poesia angolana mais actual (...) Todas essas mudanças na atitude de Maimona representam uma transgressão das formas, mais tradicionais e miméticas da poesia angolana. $\mathrm{E}$ isto supõe, além da singularização, um referente apoteótico na qualidade de recursos poéticos que marcarão um antes e um depois na literatura angolana, com Epilepsia do Planeta. (GARCIA, 2001,p. 99)

Neste lugar diferente que Maimona consolida dentro da poesia angolana, chamamos atenção para o reposicionamento do eu lírico que sempre foi grande referência de um coletivo no universo da poesia africana de língua portuguesa em geral. Assim, se pensarmos na passagem de uma voz que canta em favor de um nós e passa a cantar e a transmitir as interferências e reflexões de um eu, já estaremos dando um grande passo dentro de um terreno ainda estreito e de poucas inovações poéticas. Mas o que Maimona faz neste poemário que constitui o segundo bloco de Festa de Monarquia é uma experimentação - se assim podemos dizer - que ultrapassa a mera barreira entre o plural e o singular da voz. Nalguns momentos, Maimona silencia a voz e deixa que apenas as palavras sobrevivam e se digam sozinhas, sem a interferência ou a propriedade secundária do que é dito e as confere a responsabilidade de dizer. Assim, o poeta inaugura um novo espaço dentro de sua própria poesia, e se dedica mais intensamente às palavras como forma e potência de algo mais profundo e indizível, porém assume o risco dessa impossibilidade poética e escreve:

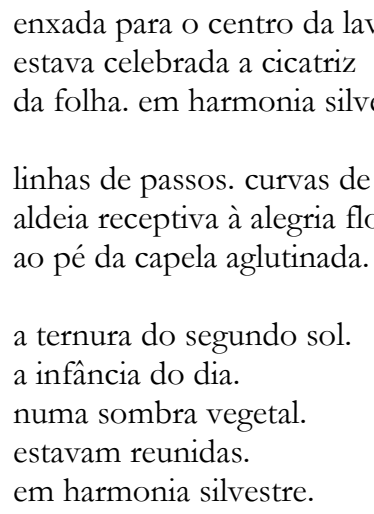

Neste poema, intitulado Passos da Enxada, percebemos a total anulação do eu lírico e da voz que venha a narrar qualquer ação ou situação em primeira pessoa. Maimona altera o rumo do coletivo e do individual enxertando espaços vazios de voz e de som, consolidando assim, o poema, na simples conjugação de metáforas e vocábulos 
redimensionados semanticamente. Essa 'aventura' de escrita resulta num campo poético pouco ou não explorado por outros autores de Angola, transformando a importância da linguagem em potência do texto e colocando-a no ponto central da criação e da análise. "Se existe poesia, é porque a linguagem é um instrumento de compreensão." Essa frase de Maurice Blanchot amarra bem a direção que tentamos apontar dentro deste poemário. O espaço do literário de sobrepõe ao pessoal (do autor) e atravessa outros entendimentos pela e com a linguagem poética. Ainda segundo Blanchot, o privilégio maior da linguagem não é o de expressar um sentido, e sim o de criá-lo. No caso específico de Maimona, de recriá-lo. Com a anulação do eu e a auto anulação que se torna inerente a linguagem, a poesia de Maimona começa a se desenhar mais próxima das imagens do que propriamente das coisas. Assim as metáforas inusitadas e os campos semânticos alusivos e herméticos remontam sentidos outros e novas perspectivas para a prática da poesia:

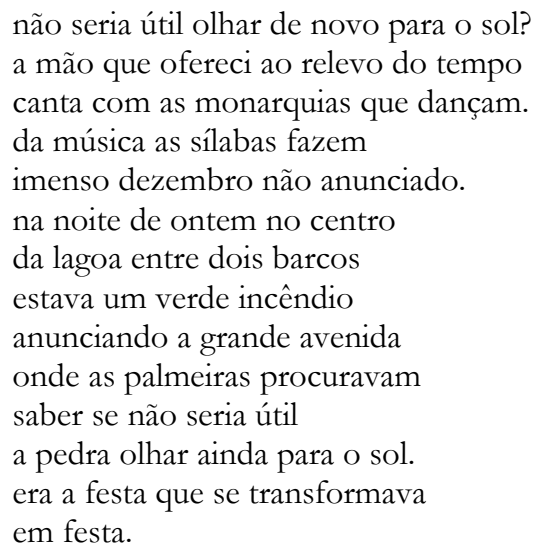

Percebemos que mesmo a rápida aparição do eu no segundo verso (a mão que ofereci ao relevo do tempo) não traz para o poema a referência do pessoal sobrepondose a relevância da linguagem. Repetem-se as imagens e a conjugação sobreposta dessas imagens, redimensionando os sentidos e as significações capazes e incapazes das palavras. A festa que se realiza ao som da música das sílabas, é uma festa de signos angolanos - lagoa, barcos, palmeiras, tempo, sol - que através do exercício com a linguagem se transforma, no final, em festa: "era a festa que se transformava / em festa." Quase um processo de adjetivação do substantivo, produzindo um efeito próximo ao executado por João Cabral de Melo Neto do poema Para a feira do livro: "O livro livro." Nesse ritmo de análise lembramo-nos novamente de Blanchot:

Como vimos, essa linguagem não supõe ninguém que a expresse, ninguém que a ouça: ela se fala e se escreve. É a condição da sua autoridade. O livro é o símbolo dessa subsistência autônoma, ele nos ultrapassa, nada podemos quanto a ele e nada somos, quase nada, no que ele é. Se a linguagem se isola do homem, assim como isola o homem de todas as coisas, ela nunca é o ato de alguém que fale para alguém que ouça, e compreenderemos por que ela oferece àquele que a considera nesse estado de solidão um espetáculo de força singular e completamente mágica. Ela é uma espécie de consciente sem sujeito que, separado do ser, é afastamento, contestação, poder infinito de criar o nada e de se situar numa falta. Mas é também uma consciência encarnada, reduzida à forma material das palavras, à sua sonoridade, à sua vida, levando a crer que esta realidade nos abre não sabemos que caminho para o fundo obscuro das coisas. (BLANCHOT, p.47)

É essa obscuridade das coisas, só atingida através da palavra, sua transfiguração real, que a linguagem poética nos proporciona em Maimona: um afastamento do real e a materialização de imagens remontadas de uma memória pessoal e coletiva. É o criar o 
nada se situando num lugar de falta, de ausência contínua que aos poucos se reconfigura através do poder que a linguagem poética adquire e converte em risco e possibilidade. Afastada do sujeito quanto a necessidade de existir, a linguagem apresenta-se capaz de dizer-se, descolada da iminente presença humana condutora. Assim seu compromisso é com ela mesma e com suas resignificações, isto é, com seu próprio espaço criado dentro do poema e potencializado como real e, simultaneamente, mágico.

A poesia em si já presume uma espécie de olhar diferente do leitor, principalmente se nos deparamos com um poeta que valoriza técnica e linguagem, como é o caso de João Maimona. Para pensar sobre poesia, é necessário investigar os menores acasos dede a folha, propriamente, passando pelos sentidos desenhados em letras até atingirmos algo que ao menos pareça válido para considerar sobre o que está escrito. Não se trata de um recorte ou de um esquartejamento qualquer sobre a leitura e os versos. O poema é um todo incompleto, repleto de brechas a serem preenchidas pelo olhar do leitor, portanto termina sempre de uma forma indefinida. Há um espaço em branco que indaga e interfere no que foi escrito. De acordo com o que se vê ao fim da leitura ou da escritura, o poema resgata a si mesmo insanamente tentando recriar-se sobre sua própria tela. A linguagem poética serve aos fins do autor que a trabalha e conduz seguindo suas intenções e técnicas. A linguagem e sua duplicidade de sentidos que quando não enganam e fracassam, fascinam e entretém.

"Chamarás poema a uma encantação silenciosa, à ferida áfona que de ti desejo aprender de cor. Ele ocorre, então, no essencial, sem que tenhamos de o fazer (...)" (DERRIDA, 1992). Este trecho de Jacques Derrida ilustra bem nossa abordagem sobre a poesia de João Maimona neste trabalho. Uma poesia que através e com a linguagem se faz independente de um sujeito maior, porém sem abandona-lo de vez. É a grande ambigüidade desse processo que, de uma forma ou de outra, continua sendo conduzido por uma mão ainda que esta não fale ou se aproprie de todo das formas e imagens do poema. São os riscos e as possibilidades de uma poesia que se encontra sempre apoiada num em falso beirando abismos da compreensão e da própria prática. São os riscos que Maimona assume dentro de um universo literário - angolano - em que não se adapta aos moldes ou tradições de escrita. Esse lugar outro inaugurado ou reinaugurado pelo poeta nas letras angolanas, aprisiona um eu e seu próprio coletivo numa ilha imagética de linguagem e resignificações. Se podemos ver signos e espaços tradicionais da cultura angolana, também podemos constatar que estes se dão por outras apresentações, formatos e inserções visuais e lingüísticas. Essa ilha de apropriações e criação habitada por João Maimona como se fosse uma aldeia de infância restaura tempo e espaço no sincronismo que há, em sua obra, no redizer das coisas. É uma nova configuração de locais conhecidos, existentes ou não, porém retrabalhados constantemente através da dinamização da palavra poética.

O poema então se faz arte de si mesmo e transporta suas próprias pretensões. Para João Maimona - inserido num espaço literário tradicional e peculiar como o angolano - isso se torna mais relevante, pois sua escrita o desloca para um lugar outro, onde habita com e na linguagem e sobrevive entre os riscos, abismos e possibilidades que a palavra impõe à escrita. Segundo Derrida, o poema é inquestionável, qualquer pergunta sobre sua existência ou nascimento ocasiona diretamente no acionamento da prosa. É assim que tentamos não questionar a poesia de Maimona e sim caminhar com ela entre veredas de metáforas esquecidas e palavras que dizem outras coisas. 


\section{REFERÊNCIAS}

BERGSON, Henri. Matéria e Memória. São Paulo: Martins Fontes, 2005

BLANCHOT, Maurice. A parte do fogo. Rio de janeiro. Rocco, 1998.

CAETANO, Íris Maria da Costa Amâncio. Diálogos angolanos: a poesia moderna e a (re) construção do passado. Dissertação de Mestrado. Belo Horizonte: Puc-minas, 1996. Texto inédito, policopiado.

CAMPOS, Haroldo de. Metalinguagem. Petrópolis: Vozes, 1967.

DERRIDA, Jacques. Che cos'è la poesia? In: Points de Suspension, Entretien. Editons Galilé, 1992.

FONSECA, Maria Nazereth Soares. João Maimona: Uma poética em desassossego. In : África \& Brasil Letras em laços. Rio de janeiro, Ed. Atlântica: 2000, P. 157 - 174.

GARCIA, Xosé Lois. O feliz retorno a origem das cosias na poesia de João Maimona. In: Festa de Monarquia. Luanda: Kilombelombe, 2000.

LARANJEIRA, Pires. A nova produção da literatura angolana. In: De letra em riste: identidade, autonomia e outras questões na literatura da Angola, cabo-verde, Moçambique e São Tomé e Príncipe. Porto: Afrontamento, 1992, p.91-105.

MAIMONA, João. Festa de Monarquia. Luanda: Kilombelombe, 2000.

MATA, Inocência. A idade maior das palavras de João Maimona; resenha do livro Idade das Palavras de João Maimona. In: Scripta, Belo Horizonte (PUC/MG), N.5, 2000.

MESTRE, David. Nem tudo é poesia. Luanda: União dos escritores angolanos, 1989.

PADILHA, Laura Cavalcante. Novos pactos, outras ficções: Ensaios sobre literaturas afroluso-brasileiras. Porto Alegre: EDUPUCRS, 2002. 